\title{
Política florestal e o quadro energético
}

John Harry Harwood *

O quadro energético atual da Amazônia indica que a região é rica em fontes de energia e que simultaneamente o consumo "per capita" é um dos menores do país.

O aproveitamento do potencial dessas fontes de energia tem que ser feito em duas escalas: 1) Assegurar o suprimento de energia para populações rurais, onde o principal problema é a baixa densidade da demanda; 2) Aproveitar em grande escala a energia para os centros urbanos onde as longas distâncias e dificuldades peculiares de transporte constituem importantes entraves à exploração dos recursos.

As fontes de energia na Amazônia são -

\section{ENERGIA SOLAR DIRETA}

A região amazônica recebe, com certas variações locais, cerca de 2.000 horas de brilho solar por ano, que apesar de não ser um dos mais altos valores mundiais, enquadra-se dentro dos limites onde o uso de energia solar é altamente atraente.

Alguns aparelhos utilizando energia solar direta são mostrados no quadro $\mathrm{I}$.

\section{QUADRO I}

\section{Conversores de Energia Solar}

1. Coletores Planos $\left(\leqslant 80^{\circ} \mathrm{C}\right)$ :

Aquecedores d'água

Destiladores

Pré-aquecimento d'água

Certos aparelhos termodinâmicos (esp. bombas)

Ar condicionado

2. Coletores concentradores $\left(\geqslant 200^{\circ} \mathrm{C}\right)$ :

Fogão

Forja

Máquinas a vapor e outros aparelhos termodinâmicos, inc. geradores

Refrigeração

3. Células fotovoltáicas $(\leqslant 4 \mathrm{WK})$ :

Estações repetidoras de telecomunicação

Luzes de balizamento para navegação

Radiofaróis

4. Termopares:

Raras aplicações de baixa potência
Os aparelhos solares são, em geral, de baixa potência e autônomos o que os faz adequados ao uso em populações rurais. Contudo, há restrições sérias à implantação dessa tecnologia a curto prazo, já que a maioria dos aparelhos estão ainda na fase de pesquisa ou de escala-piloto.

A célula fotovoltáica que transforma energia solar em elétrica apresenta-se extremamente promissora, estando ainda seu uso limitado a aplicações específícas dado o seu alto custo. Há expectativas de que em breve seu custo de produção diminua, chegando futuramente ao ponto de ser competitiva com outras fontes.

$E$ importante que as autoridades governamentais acompanhem atentamente o desenvolvimento da tecnologia solar, estimulando a pesquisa e incentivando a fabricação nacional.

As implicações a floresta na utilização de aparelhos solares são mínimas, limitando-se somente ao espaço físico ocupado pelo equipamento.

\section{ENERGIA HIDRÁULICA}

A Amazônia é a região do mundo cơm maior quantidade de água doce em movimento. O potencial hidráulico é conseqüentemente enorme. Basicamente podem distinguir-se três tipos de potencial hidráulico:

a - Altas quedas

b - Baixas quedas

c - Energia de correnteza

A tecnologia de exploração de altas quedas é bem conhecida e o potencial regional enorme (ex: 100 milhões de KW só nos rios da margem direita do Amazonas). Os fatores limitantes na exploração dessas fontes têm sido as dificuldades de acesso e ou falta de consumidores dentro do raio de distribuição.

As conseqüências ambientais da exploração de altas quedas surgem da construção de represas inundando grandes áreas de floresta que em seguida morrem. As condições físico- 
químicas da água se alteram impondo modificações na flora e fauna aquáticas. A barragem constitui uma descontinuidade no curso do rio afetando-o acima e abaixo dela.

Em princípio, os custos ecológicos parecem baixos, mas não podem ser negligenciados, como os ecossistemas são diferentes de lugar para lugar, cada um deve ser analisado individualmente.

É importante completar o levantamento dos recursos hídricos pormenorizadamente para poderem demarcar-se as possíveis áreas de inundação para evitar conflitos de interesse no planejamento de estradas, reservas florestais e indígenas, regiões de exploração mineral, etc.

Usinas de baixa queda, freqüentemente chamadas de usinas de bulbo, apresentam as mesmas conseqüências ambientais das usinas de alta queda, porém com menor intensidade visto que são, normalmente, usinas pequenas. A tecnologia ainda é incipiente no Brasil, mas parece bem apropriada à região amazônica. Permite gerar quantidades de eletricidade adequadas às necessidades das cidades do interior tornando-as energéticamente autônomas.

O aproveitamento da energia de correntezas de água (sem queda) usando rotores submersos de baixa velocidade é um novo campo de pesquisas que está recebendo atenção em várias partes do mundo ( $\mathrm{p}$. ex. Fraenkel \& Musgrove, 1979) . O impacto da utilização desta tecnologia será provavelmente na geração de eletricidade ou força-motriz em escala individual pelos moradores ao longo das margens dos rios, embora unidades consideravelmente maiores sejam possíveis. As conseqüências ecológicas desses rotores seriam mínimas.

E importante lembrar que o cálculo dos recursos hídricos está baseado nos níveis de precipitação atuais que dependem da evapotranspiração atual, que por sua vez depende do tipo de cobertura do solo. É possível que um desmatamento em grande escala para fins de agropecuária ou outros possa ocasionar uma mudança significativa nos níveis de precipitação. Embora este fenômeno até agora não se tenha verificado na prática, a magnitude do desastre potencial é tal que merece uma pesquisa intensa e constante.

\section{ENERGIA DE BIOMASSA}

Biomassa contém, em geral, alto valor calorífico e certos produtos biológicos já vem sendo usados em grande escala no panorama energético nacional. Por exemplo o consumo de lenha, bagaço-de-cana e carvão vegetal, juntos, equivaleu em 1977, a duas vezes o consumo nacional de gasolina. (Ministério de Minas e Energia, 1978) .

As possiveis fontes de energia provindas de biomassa na região Amazônica são: a) Biogás, b) Madeira e derivados, c) Etanol, d) Oleos vegetais.

BIOGÁS

Biogás é uma mistura de metano $(60 \%)$ e gás carbônico $(40 \%)$ formado quando a matéria orgânica fermenta anaerobicamente próxima do $\mathrm{pH}$ neutro. É um combustível rico em energia, versátil e limpo. A tecnologia de produção é muito simples e pode ser usada com uma grande variedade de resíduos orgânicos.

A produção de biogás a partir de esterco de gado é uma tecnologia plenamente estabelecida aplicada em grande escala na India. Na. região amazônica é de maior interesse produzir biơgás por meio de plantas ou resíduos agrícolas em virtude da imensa quantidade de biomassa vegetal presente no local. Essa adaptação da tecnologia indiana às circunstâncias amazônicas está sendo pesquisada atualmente.

Dada a baixa velocidade de reação durante a produção do biogás é pouco provável que este processo venha a ser usado em circunstâncias outras que não o aproveitamento de restos.

A utilização do biogás traz uma vantagem não energética na medida que o efluente líquido do biodigestor é normalmente de alto valor fertilizante e também um bom condicionador físico do solo. Este fato é muito importante numa região como a Amazônia, onde o solo é pobre.

\section{MADEIRA E DERIVADOS}

A maneira tradicional de se extrair energia da madeira é queimá-la. Para produção de energia elétrica ou força motriz em escala 
pequena se usa, normalmente, um locomóvel (máquina a vapor). A eficiência deste é da ordem de $13 \%$, contudo, este baixo rendimento é compensado pelo baixo custo de matériaprima. Em escala maior, está projetado o uso de turbinas a vapor com uma eficiência de $25 \%$.

Outras formas de utilização de energia da madeira são: gaseificação com ou sem produção de metanol, produção de carvão vegetal e hidrólise para produzir etanol. Gaseificação de madeira para uma substituição parcial de óleo diesel em motores estacionários é uma tecnologia estabelecida pela firma francesa Lacotte e utilizada na usina-piloto da Companhia Energética de São Paulo (CESP) com uma economia de $85 \%$ de óleo diesel (Leite, 1979). A produção de metanol usa um gasogênio similar ao de Lacotte mas o gás segue uma série de reações terminando na formação do metanol. Cerca de $38 \%$ da energia inicial na madeira é obtida no produto final (Hokanson \& Rowell, 1977).

A produção de carvão vegetal é uma atividade tradicional. O produto é de interesse porque queima sem fumaça e impurezas o que permite o uso em fogões domésticos e em gasơênios para substituir gasolina em motores a explosão. O país não dispondo de carvão mineral para a obtenção de coque, o carvão vegetal tornou-se indispensável para a produção de aço. Na Amazônia a indústria de carvão fica quase sem infra-estrutura enquanto que tecnicamente existem boas possibilidades de valorizar a madeira dos desmatamentos transformando-a em carvão. A implantação da infra-estrutura necessária pode ser a nível de governo ou da iniciativa privada.

A produção de etanol por hidrólise da madeira e fermentação é uma tecnologia estabelecida em vários países (Galuff, 1979) e merecendo muito interesse atualmente.

A viabilidade econômica de implantar qualquer indústria de conversão de madeira em energia depende de muitos fatores, mas é importante lembrar que uma indústria baseada na madeira recebe um incentivo enorme do ponto de vista de que ela pode aproveitar não somente de um plantio de energia mas tam- bém da madeira da floresta já existente no local. Por exemplo: uma turbina a vapor usando energia de eucalipto plantado com uma safra média de 12 toneladas de madeira por hectare por ano, pode inicialmente aproveitar da energia da floresta natural a quantidade de 200 ton/ha (Uhart, 1976) o que equivale a um "prêmio" de 17 anos de produção. Também há possibilidade de usar-se a floresta antes de um plantio de madeira, permitindo que a indústria transformadora opere desde o início sem ter de esperar o primeiro corte do plantio energético.

Neste momento, vastas quantidades de energia são gastas durante o desmatamento por queimadas e também na queima de restos da indústria madeireira. Apesar da abundância do combustível, é necessário que haja uma confiável infra-estrutura intermediária entre a extração/produção e o uso. A falta desta infra-estrutura era uma das causas da falha de muitos locomóveis em pequenas comunidades do interior. Em tais comunidades com uma demanda de cerca de $100 \mathrm{KW}$ é desejável que a geração de eletricidade seja ligada à indústria madeireira.

A solução, a longo prazo, do abastecimento em madeira para qualquer dos usos citados é o reflorestamento. Técnicas apropriadas têm que ser pesquisadas, mas a produtividade de florestas plantadas expressa em $\mathrm{kcal} / \mathrm{ha} /$ ano é potencialmente maior do que a utilização de cana-de-açúcar (Quadro II) .

\section{ETANOL}

A produção do combustível líquido etanol a partir da fermentação de plantas ricas em açúcar está sendo promovida pelo governo através do PROALCOOL. Como é mostrado no quadro II, a cana-de-açúcar dá o melhor rendimento deste produto. Contudo produtos tradicionais da região como a mandioca são de interesse porque sua forma de cultivo já é bem conhecida.

E importante que qualquer incentivo para a produção de mandioca para fins energéticos leve em conta a situação alimentar, já que o Estado do Amazonas não é auto-suficiente neste produto. Os problemas sociais causados 
QUADRO 11

Dados comparativos de produção de combustivel a partir de algumas plantas

\begin{tabular}{l|l|c|c|c}
\hline \multicolumn{1}{c|}{ Combustivel } & \multicolumn{1}{|c|}{ Origam } & $\begin{array}{c}\text { Produçáo Média } \\
\text { (Ton./ha/ano) }\end{array}$ & $\begin{array}{c}\text { Calor de Combustão } \\
\text { (Kcal/Kg) }\end{array}$ & $\begin{array}{c}\text { Energia Obtida } \\
\text { (105 Kal/ha/ano) }\end{array}$ \\
\hline Lenha & Eucalipto & 12 & $2.000^{2}$ & 24 \\
Álcool & Cana & $2,41^{2}$ & 7.121 & 17 \\
Alcool & Mandioca & $1,73^{2}$ & 7.121 & 12 \\
Alcool & Babaçu & 0,192 & 7.121 & 1,4 \\
Álcool & Batata doce & $1,5^{2}$ & 7.121 & 11 \\
Hidrocarbonetos & Aveloz & $0,53-2,65^{2}$ & 11.000 (aprox.) & $5,8-29,2$ \\
Terpenos & Marmeleiros & $0,36-1,792$ & 11.000 (aprox.) & $3,9-19,7$ \\
Oleo & Dendê & 4 & 11.000 (aprox.) & 44 \\
\hline
\end{tabular}

i. Uhart (1976).

2. Croveiro et al. (1978).

por um possível encarecimento deste alimento básico, tem que entrar no balanço de custo/ benefício quando se pretende transformar alimento em combustível.

\section{ÓLEOS VEGETAIS}

Como mostra o quadro II, a produção de óleos vegetais para fins energéticos é potencialmente muito importante.

Estes óleos são de interesse não apenas em face da alta produtividade mas também porque representam possiveis substitutos para o óleo diesel dado o seu alto índice de cetano. $O$ álcool tendo um baixo índice de cetano (alta octanagem) não é apropriado para esta substituição sem o uso de aditivos caros.

Pesquisas agronômicas sobre a produtividade de plantios de oleaginosas sob condições locais são necessárias e será desejável começar o mais cedo possível, visto o longo prazo para desenvolver essas pesquisas.

\section{LINHITO}

Linhito é um mineral que apresenta propriedades intermediárias entre a turfa e o carvão mineral.
No alto Solimões existem camadas de linhito com a espessura média de $30 \mathrm{~cm}$ estendendo-se por $500.000 \mathrm{~km}^{2}$. As características físico-químicas do linhito estão apresentadas no quadro III.

\section{QUADRO III}

Características do Linhito no Alto Solimões (Sousa, 1979).

\begin{tabular}{l|c|c|c}
\hline Características & Mínimo & Máximo & Média \\
\hline & & & \\
Poder calorifico & $729 \mathrm{Kcal}$ & $5.871 \mathrm{Kcal}$ & $3.300 \mathrm{Kcal}$ \\
Unid. higroscópica & $3,1 \%$ & $34,2 \%$ & $18 \%$ \\
Teor de cînzas & $10,3 \%$ & $83,3 \%$ & $46,8 \%$ \\
Carbono fixo & $5,0 \%$ & $47.5 \%$ & $26 \%$ \\
Materiais voláteis & $14,1 \%$ & $58,9 \%$ & $36 \%$ \\
Enxofre & $0,4 \%$ & $15,3 \%$ & $7,8 \%$ \\
Peso específico & 1,63 & 2,7 & 2,1 \\
"Free Swelling & & & 0 \\
Index" & 0 & 0 & 0 \\
\hline
\end{tabular}

A conclusão de Sousa (1979) é que o linhito do Solimões tem que ser classificado como "linhito no limite superior da turfa". isto é com baixo grau de maturidade. Ele sugere o uso do linhito para fins de gaseificação e não como carvão-vapor dado o alto teor de cinzas $(46 \%)$ e enxofre $(7 \%)$. A exploração deste 
linhito precisa ainda de mais pesquisas, mas a mineração será a céu aberto o que acarretará problemas ecológicos de grandes dimensões. Sobretudo qualquer exploração precisa de pesquisas na reutilização do solo após a extração do mineral. Dado o tamanho da área de possivel devastação, a exploração tem que ser precedida de uma usina-piloto $(p$. ex: fornecimento de energia elétrica por via de gaseificação de linhito para uma pequena municipalidade) antes de embarcar precipitadamente num projeto mais amplo. Também no planejamento de reservas florestais e outras áreas de preservação, será prudente evitar as áreas mais promissoras para a extração de linhito.

\section{PETRÓLEO E GASS NATURAL}

Prospecções intensivas estão em andamento na Amazônia. Quantidades comerciais de gás existem e as formações geológicas são apropriadas para a ocorrência de petróleo, embora ainda não tenha sido encontrado em importantes quantidades. Sem dados precisos dos reservatórios é difícil comentar sobre o impacto ambiental dessas fontes de energia.

Os principais depósitos conhecidos estão apresentados no quadro IV.

QUADRO IV

Ocorrência de hỉdrocarbonetos na Amazônia

\begin{tabular}{l|l|l}
\hline \multicolumn{1}{c|}{ Bacia } & \multicolumn{1}{|c|}{ Depósito } & Hidrocarboneto \\
\hline $\begin{array}{l}\text { Médio Amazonas } \\
\text { Médio Amazonas }\end{array}$ & $\begin{array}{l}\text { Nova Olinda } \\
\text { Autás Mirim } \\
\text { Alto Amazonas }\end{array}$ & $\begin{array}{l}\text { Petróleo } \\
\text { Petróleo } \\
\text { Juruá I }\end{array}$ \\
\hline
\end{tabular}

Ponte et al. (1979).

\section{CONCLUSÕES}

Recomendações específicas são apresentadas no corpo deste trabalho para cada uma das fontes energéticas analisadas. Em termos globais, na região amazônica, não há falta de energia. O problema é de transformar a energia das várias forites em (1) eletricidade e (2) combustivel liquido para transporte.
As perspectivas para o suprimento de energia elétrica são boas com o uso da tecnologia de baixa queda para as pequenas comunidades e com grandes barragens de alta queda fornecendo energia elétrica aos grandes centros urbanos, dentro e fora da região. Em escala local a biomassa pode fornecer energia elétrica em lugares dificilmente atingidos por uma rede de hidreletricidade. Várias tecnologias existem para esta transformação mas os princípios são sempre os mesmos: aproveitamento de resíduos ou de plantiơs sustentáveis a longo prazo. $O$ assunto de plantios energéticos ainda necessita de pesquisas para um aproveitamento adequado na Amazônia.

As fontes de combustíveis líquidos serão metanol de madeira, etanol de madeira, cana, mandioca e óleos vegetais. A produção destes deve levar em conta as mesmas diretrizes de aproveitamento de restos e plantios renováveis adaptados à região. Provavelmente, não há uma só solução, por exemplo metanol ou etanol de madeira serão favorecidos em regiões hoje cobertas de florestas (para aproveitar a madeira em pé\}. O etanol de cana será favorecido em locais já desmatados onde este "prêmio" não existe. Óleos vegetais são de interesse como substitutos de óleo diesel.

A exploração de linhito implica em uma devastação do ambiente pior que um desmatamento predatório e qualquer utilização deste recurso deve ser planejada com extremo cuidado.

Nenhuma diretriz foi sugerida neste trabatho acerca de petróleo e gás natural.

\section{BIBLIOGRAFIA}

Cravfiro, A.A. et al.

1978 - "Possibilidades do Uso de Oleo Essencial do Marmeleiro como Fonte não Convencional de Energia". Ciência e Cultura, 30(8) : 994-996.

Fraenkel, P.L. \& MUSGrove, P.J.

1979 - "Tidal and River Current Energy Systems". Trabalho apresentado à Conferêncla de "Conceitos de Energia Futura", promovido pelo Instituto de Engenheiros Elétricos Londres. 
GalufF, C.N.

1979 - "Recursos Florestais: uma Fonte Energética Subutilizada". Seminárío sobre o modelo energético Brasileiro, promovido pela Rede Globo, Ministério de Minas Energia e SECOM - Manaus.

Hokanson, A.E. \& RoweII, R.M.

1977 - "Methanol from Wood Waste". United States Department of Agriculture, General Tecnical Report FPL 12.

LEITE, A.R.C.A.P.

1979 - "Aplicações da Gaseificação da Madeira na Geração de Energia". Trabalho apresentado ao Simposio sobre Fontes Alternativas para Geração de Energia Elétrica, promovido pelas Centrais Elétricas do Amazonas-Manaus.
Ministério de Minas e EnERgia.

1978 - "Balanço Energético Nacional".

Ponte, F.C.; Dauzacker, M.V. \& Porto, R.

1979 - "Origem e Acumulação de Petróleo nas Bacias Sedimentares do Brasil". Atualidades do Conselho Nacional do Petróleo, $66: 16-42$.

SOUSA, J.F.

1979 - "Possibilidades energéticas do Linhito do do Alto Solimões". Trabalho apresentado ao Simpósio sobre Fontes Alternativas para Geração de Energia Elétrica, promovido pelas Centrais Elétricas do AmazonasManaus.

UHART, E.

$$
\begin{aligned}
& 1976 \text { - "A Floresta Amazônica: Fonte de Energia" } \\
& \text { - SUDAM. }
\end{aligned}
$$

